\title{
Risk Management Application in an Oil and Gas Company for Projects
}

Fatema Abdulla AINoaimi*

Master of Science in Engineering Management

The George Washington University

United States Washington, DC

E-mail : alnoaimi.fatemaa@gmail.com

*Corresponding Author

\section{Thomas A. Mazzuchi}

Master of Science in Engineering Management

The George Washington University

United States Washington, DC

E-mail : $\underline{\text { mazzu@gwu.edu }}$

Received May, 2021; Accepted August, 2021

\begin{abstract}
Oil and gas projects are at high risk and the reasons can be the adoption of complex technology, participation of different parties, etc. Oil and gas industries are often vulnerable to risks and hazards, but they overcome these problems by following tools and techniques of risk management, which results in employee and organizations safety. Based on the facts, this research report aims to evaluate and identify the risk management strategies and procedures and assess the efficiency of risk management tools in the Oil and Gas Company in the Kingdom of Bahrain. The survey was conducted among two groups using quantitative as well as qualitative methods. One hundred twenty-four participants comprising of Engineers, Superintendents, Fire and Safety Officers, HR Managers, Health and Safety Environment Officers were among the respondents of the Survey Questionnaire. For the semi-structured interview, managers from supply and marine, Operation Specialist, Acting Manager of Health, Safety and Environment (HSE), Managers of Operational Plant Department were selected. The data collected through the survey question was analyzed using statistical analysis. The data collected through the survey questions were later imported to IBM SPSS (Statistical Package for Social Science) version 23.0 and performed descriptive analysis to explain the participants' characteristics, discrete variables expressed as frequencies and percentages and continuous variables expressed as mean and SD. The reliability of the instrument was assessed using Cronbach's alpha. This research indicated that around $56 \%$ of the engineers and majority of the participating managers agree and strongly agree that the company has the Oil and Gas Company in the Kingdom of Bahrain have has implemented several safety precautions, training, and appropriate risk management tools to ensure the safety of the employees and work to eliminate any risk which could be hazardous to life and property.
\end{abstract}

Keywords: Oil and Gas company, Risk and Hazard factors, Project Risk Management, Risk Management tools and practices.

Type: Research paper

\section{Introduction}

\subsection{Background}

Risk management is a system that assures continuous improvement and progress in work application and implies to organizations decision making. Risk management can be 
employed in an organization to avoid crisis and it also beneficial in building the organizations value. Good management practices always consider risk management as an important asset and a fundamental part of smooth work environment as per Wilson.r and Shlyakter (1997). Recently, concept to risk management becomes highly popular in many organizations and companies. To mitigate the right economic budget and for reducing project associated risks, many times construction companies with wide and complex projects are keen to adopt the risk management practices. To improve performance and profit, many oil and gas companies started to establish risk management procedure. Usually, different type of businesses, projects and profession have their own kind of risk descriptions, meanings and management strategy, it depends on every one's perception and understanding in the team as mentioned by Samson S, Reneke JA \& Wiecek MM.(2009). Some conditions always put oil and gas project at high risk and the reasons can be adoption of complex technology, participation of different parties etc. A risk can be defined as a series of unplanned unwanted events which have an ileitis to change the probability prospects of a given investment as per An Enhassi, J A Mosa. (2008).

\subsection{Research Problem}

Many organizations with high project budget and less monitoring usually suffer economically and have to pay the cost of negligence. Organizations have to face loss of value, and bad impressions due to lacunas like miss communications, lack of governance and missing information as mentioned by Fauver and Naranjo (2010). Oil and gas industries often vulnerable to risks and hazards, but they overcome these problems by following tools and techniques of risk management, which results in employee and organizations safety. All this evidence is a result of small negligence and improper monitoring by management. Hence it is vital to incorporate several precautionary measures and risk management strategies for oil and gas industry.

\subsection{Study Purpose}

The aim of this study is to identify how risk management can be applied in oil and gas companies. As EY. (2014), Suda, Rahman, Rani, \& Chen. (2015) mentioned in their studies, various surveys states that, numerous oil and gas companies are unsuccessful in reaching the target due to time schedule, quality and budget in line to this project risk management can proved to be a vital to identify all risks that hampers company performance. Project risk management is keen to identify assessment, monitoring and controlling unexpected risks.

\subsection{Statement of Problem}

During the management of projects, managing risk is the most essential concept because unexpected risks can directly influence all project participants' benefits. This paper will be helpful in identifying and classifying all the risk factors based on different risk sources, in particular aim of this pater is to provide the outline of risks relevant to oil and gas company projects and evaluation of measures and effectiveness of the risk management strategies applied. 


\subsection{Research objectives}

- To identify risk management strategies and their application for projects in an oil and gas company.

- To identify the procedures of implementation of risk management strategies and to measure the efficiency of risk management tools applied in company.

- To provide the practical feedback based on the result and findings.

\subsection{Research questions}

- What are the major risks and issues that influence the projects in oil and gas industries?

- What are those standard guidelines and procedures applied during risk management in oil

and gas project site?

- How effective are the current risk management tools and strategies in identifying and managing risks?

- What is employee's extent of involvement in project risk management strategy?

- What safety precaution and pre-planning of risk management are applied to ensure human and environment safety?

\subsection{Scope of the Research}

This study involves identifying the practices of managing risk in the oil and gas companies. The major area of interest of this study is to find out the major risk factors faced during projects, and different risk management and tools adopted to control the risks. This study also focuses on the behavioral characteristics of project managers and employees involved in projects in oil and gas industry.

\section{Literature Review}

\subsection{Introduction}

As Herkenhoff (2014) stated in his paper, the oil and gas industry significantly influence all aspects of other businesses and economy of all countries. All countries are affected by any fluctuation in oil and gas industry because they are either producer and /or consumer of oil and gas or both the oil and gas industry strategically most important to the global economy. The reality is every country's' economy actively affected by the oil and gas industry, in one way or another as mentioned by Schwab (2016).

Many researchers stated that even if a various alternative emerge as energy source but still oil and gas will remain most important sources of energy for upcoming decades as per the report by BP \& England, (2016). For resources and project implementation their oil and gas companies rely on number of specialised professionals in relevant fields. State companies in the Middle East are in control of the major portion of the total global oil reserves as per report by the Petroleum.co.uk, (2015). 


\subsection{Risk}

N. Thuyet and S. Ogunlana (2007) stated in his paper that Risk factor in process of development many times caused time and cost complexities. Many tasks in project have been exceeding the spending limit; these issues are more common now days.

Risk can be characterized as a problem that may cause bad luck in achievement of success. Risk management can be said as key business process, where by managerial team needs to evaluate reliability of goals and risk management strategies in relation to development and success of company as per J.C. Clarke, and S. Varma (1999).

\section{Potential Risks in Oil and Gas Projects}

Following are the integral risks for functioning of oil and gas companies: -

1. In every project there are some internal risks such as financial, investment, property, human resources, management, innovations, information, production operational, technical, technological, liquidity etc. Investment risk can be arising as a result of low legal of attraction of investment projects. Property risks are reflected by low level of liquidity, solvency and business activities etc...

2. Extreme risk lime political pressure, legal issues, socio-demographic, ecological, market problems, exchange, repayment, geological, weather, globalization are also recognized according to Khvostina et.al, (2019).

3. The information risk may arise because of gap in information system among organization.

4. Geological risks can be observed to affect oil and gas extraction process and can be result in insecurity about the productivity of deposits.

5. Globalization risks can cause the end of not only particular enterprises but also the whole industry or another company. If oil and gas activities are not controlled and regulated properly, it can cause a considerable loss of environment, become dangerous to life and property as stated by Achaw, Osei-Wusu, and Boateng. (2012).

In addition to these problems oil and gas industry frequently faces the threat of gas leakage and often brings out the social conflicts and casualties as Ambarsari, DC et al. (2009) mentioned in his paper. These disasters are not possible to avoid but they can occur at any time, by considering the potential risks the management measures can be applied according to Voogd Henk. (2004.) 
These hazards can be classified in 3 major categories:

1. Natural hazards: These kinds of hazards arise due to change in climatic and geographical aspects.

2. The technological hazards can cause loss of life, property damage, socio-economic disturbance, and environmental degradation.

3. Environmental degradation can be deteriorating important natural resources, or negative alteration in ecosystems. The environmental deterioration can cause by influential activities of human, sometimes combined with natural disasters.

\section{Risk emergent properties at oil and gas industry}

According to the authors Babenko.V.et.al. (2018) and Ivashuk. yu. P. (2016), concept of emergence is a result of reflection of a situation when strategic interaction of an individual gives overall positive effect. Oil and gas companies have to face loss or crisis for business entities, due to any single identified risk. Monitoring of negative events should predict the risks caused by the emergent properties of risk. If risk emergent properties are involved during risk analysis, it helps to identify both future hazards and upcoming new opportunities in the enterprise development. For example, to reduce the risk of environmental pollution and degradation, it is essential to adopt international environmental quality standards. This can manage legal and environmental risks as stated by Khvostina Inesa et.al (2019).

\subsection{Management of Projects in oil and Gas Industry}

The Panel BS6079 11996 as the preparation, observation and control of all parts of a challenge as well as the motivation of all of those connected with it, according to the British Standard for venture, to achieve the venture goals in a timely manner at defined expense, efficiency and execution. Management has to manage both expectations as well as experiences within the boundaries and abilities of its partners. Managerial accomplishment is an uncertain, detailed and diverse field and its showing is estimated.

\section{Risk Management Concept}

Many organizations recognized the perception as well as the significance of risk management in projects as stated by Cooper et al., (2005). This process cannot be separated from man tasks and functions in project management, but it is fundamental towards the bigger project managing procedure as reported by Cooper et al., (2005) and PMI, (2013). Project risk management has a strong foundation in improvement of Program Evaluation and Review Techniques (PERT) during the 1950s' with focus on dealing with ambiguity in the duration of the project according to Taroun, (2014). Different disciplines like economy, management strategic management, and project 
management study the concept of risk and risk management but all disciplines view the concept differently. Reviewed literature by Ehsan (2013) also states that, there is no perfect and standardized definition of these terms available. Besner and Hobbs (2012), defined project risk management is an organized practice to effectively manage project risks. In addition to this scholars and professional bodies define the concept with slight differences in the level of details, as, risk management process is a 5-step process: risk identification, risk assessment, risk classification, risk mitigation and risk controlling;

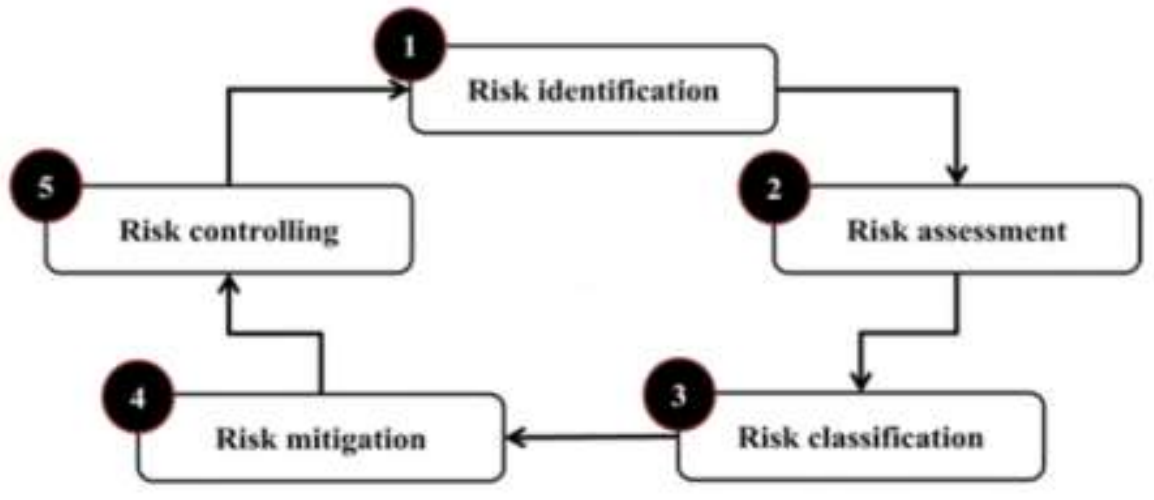

Figure 1 Project Risk Management Process

\subsection{Benefits of project risk management in oil and Gas Industry}

The Oil and gas industry procedures are oriented as per the demand of global energy as well as different projects undertaken are the backbone of these companies. Therefore, the key goal of risk management practices is shortening the time required for risk identification, undertaking clear risk evaluation procedure, strategizing actions and finally providing report on the identified risk. In addition, PMI (2004) stated that, risk management practices not only identify and reduce product's risk levels but also include planning of risk management it's monitoring and control process.

\subsection{Risk Management Practices in oil and gas industry}

While anticipating the project-related injury and sickness risk management is very important. It incorporates:

- $\quad$ Identifying the dangers

- $\quad$ Evaluating and organizing the dangers

- Implementing preventive/defensive measures to control the risk. Hairdos S. (2017)

There are several circumstances in the Oil and Gas industry where a proper risk management process is essential:

1. Job safety analysis.

2. Government Limitations. 
3. Environmental Constraints.

4. Supply and Demand.

5. Cost.

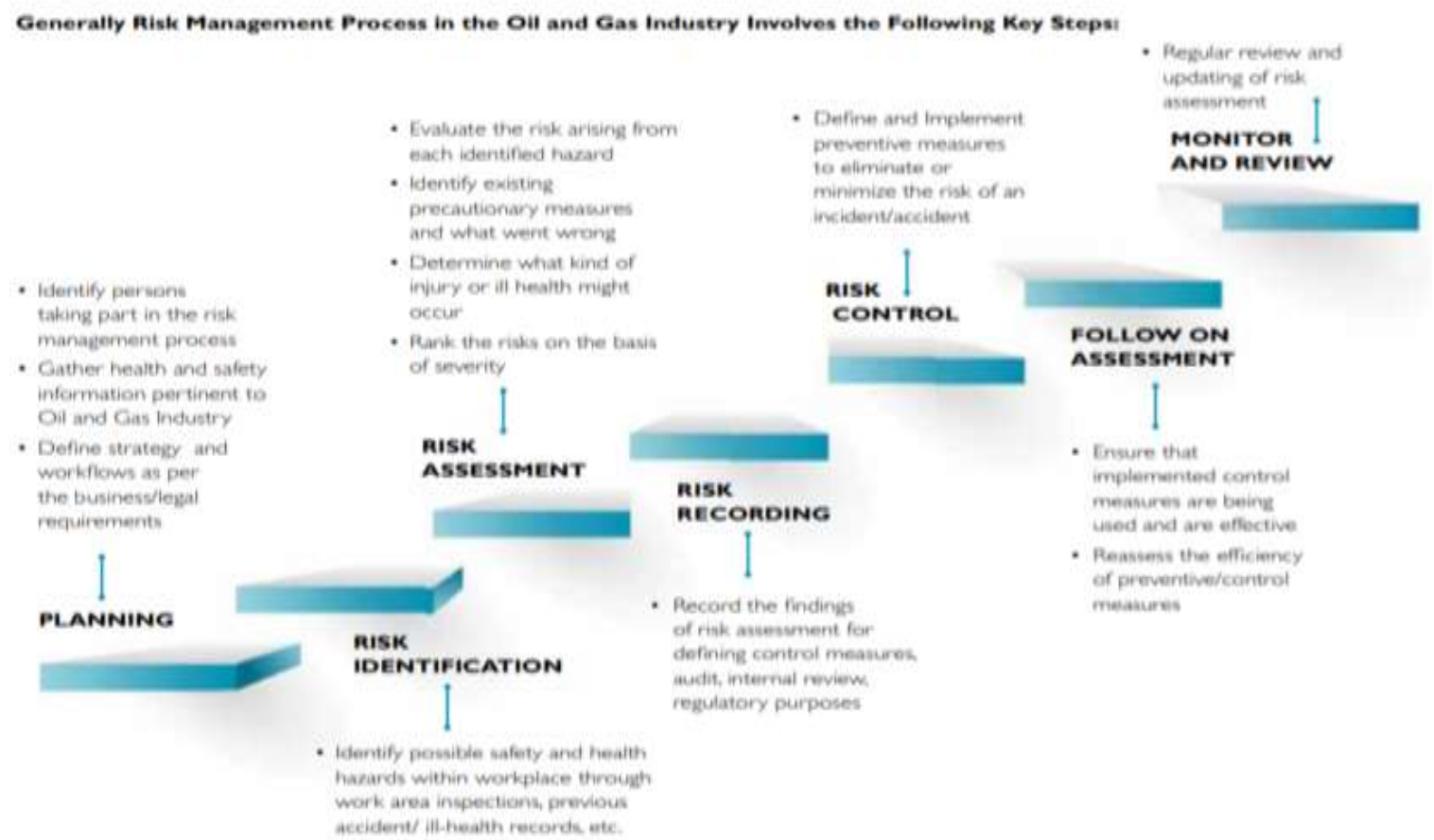

Figure 2 Project Risk Management Process

\subsection{Risk Management Process}

\section{Risk Identification Project}

The risk identification project is primary exercise of risk management. During the early phase of project, this stage plays an important role of identification, classification and assessment of importance of project risks as mentioned in the paper by Aven et al., (2007). After proper documentation, classification the risk is recognized in the records. The management should communicate to all the team members and should explain the potential consequences of risk as reported by PMI (2013).

\section{Risk assessment}

Study and observation of sequence of events taking place around the 'risk' is important for establishment of risk assessment. This sequence of events can be the cause of risk occurrence and consequences. According to Cagliano et al., (2015) these three events can be converted into phases of risk management process, involving planning, identification, analysis, monitoring, response and control of the risk. Zwikael \& Ahn, (2011) stated in their paper that many projects have to face failures because their risk assessment team unable to understand and identify possible sources of project risk, especially in Middle East and North Africa (MENA) region assessment teams inability to accurately score the risk for various projects is observed as mentioned by Srivastava \& Gupta, (2010). 


\section{Project Risk Response}

In this process, creating a risk response plan is also necessary task. Developing a risk response plan can include defining thresholds and activates, emergency strategies and justification schemes etc. Risk response matrix can also be applied to determine the risk response plans and actions. The mutual risk response policies recognized are: avoid, transfer, reduce and accept.

\section{Risk Control}

Controlling risk factors is another important part of the project risk management practice. This activity is done continuously over the project life cycle. Project risk control involves the reassessment of all possible project risks and finding more effective risk management plan of risk response action as mentioned by Benta et al., (2011).

\subsection{Tools and techniques to support risk management}

The review of literature by Cagliano, Grimaldi, \& Rafele, (2015); Salazar-Aramayo et al., (2013) in this research area suggests at least 31 tools and techniques to support project risk management. These tools and techniques are showing suitability-based nature, size and complexity of the project undertaken.

\begin{tabular}{|r|l|r|l|}
\hline 1. & Checklist & 2. & Brainstorming \\
\hline 3. & Change Analysis & 4. & $\begin{array}{l}\text { Failure Mode and Effect Criticality } \\
\text { Analysis (FMECA) }\end{array}$ \\
\hline 5. & Decision Tree Analysis & 6. & Cause and Effect Diagram \\
\hline 7. & Fault Tree Analysis & 8. & Expert Judgement \\
\hline 9. & FMEA & 10. & Fuzzy Logic \\
\hline 11. & Event Tree Analysis & 12. & Delphi \\
\hline 13. & Expected Monetary Value & 14. & Hazard and Operability \\
\hline 15. & Human Reliability Assessment & 16. & Hazard Review \\
\hline 17. & Interview & 18. & Incident Reporting \\
\hline 19. & Pareto Analysis & 20. & Monte Carlo \\
\hline 21. & Preliminary Hazard Analysis & 22. & Probability Index Matrix, Risk Matrix, \\
& & Risk Mapping \\
\hline
\end{tabular}




\begin{tabular}{|r|l|r|l|}
\hline 23. & Sensitivity Analysis & 24. & $\begin{array}{l}\text { Risk Ranking / Risk Probability and } \\
\text { Impact }\end{array}$ \\
\hline 25. & Swift Analysis & 26. & $\begin{array}{l}\text { Strengths, Weaknesses, Opportunities } \\
\text { and Threats }\end{array}$ \\
\hline 27. & "5 whys" Technique & 28. & What-if Analysis \\
\hline 29. & $\begin{array}{l}\text { Risk Breakdown Matrix } \\
\text { 31. }\end{array}$ & $\begin{array}{l}\text { Event and Causal Factor } \\
\text { Charting }\end{array}$ & Risk Breakdown Structure \\
\hline
\end{tabular}

Table 1 Risk Management Tools \& Techniques

\subsection{Selecting an effective project risk management tool or technique}

Selection of perfect risk management tools and techniques is an important task in ensuring the success of project. Selection of risk management tools and techniques can be varying according to project, because specific projects can differ in their nature, location, size and complexity as per Cagliano et al., (2015), to ensure the performance of different kind of projects in different working environments tools and techniques can be selected as per Liu, Meng, \& Fellows, (2015).

\subsection{Phase of the risk management process}

Hillson \& MurrayWebster, (2007) in their paper stated that risk management process is practically based on the sequence of events; those are responsible for risk emergence these events can be a cause of risk, occurrence of risk and consequences responsible for risk . Risk management involves identification, planning, analysis, monitoring, responses, and control of risk as mentioned by Cagliano et al., (2015).

\subsection{Challenges in developing effective project risk management practices}

As Nocco \& Stulz, (2006) stated in their paper that although, project risk management practices may look simple and impressive I theory, practically difficult for implementation. One more difficulty in Implementation of project risk management strategy is, company cannot put all responsibilities on an employee at different levels of company. Goh and Abdul-Rahman (2013) found that lack of knowledge in employees or among different parties about the overall benefits of project risk management can lead to failure in achieving company goals. Dandage et al. (2017) conducted a detailed literature review and identified 10 important challenges and barriers that can be proved a limiting factor in development and application of successful project management, including: 


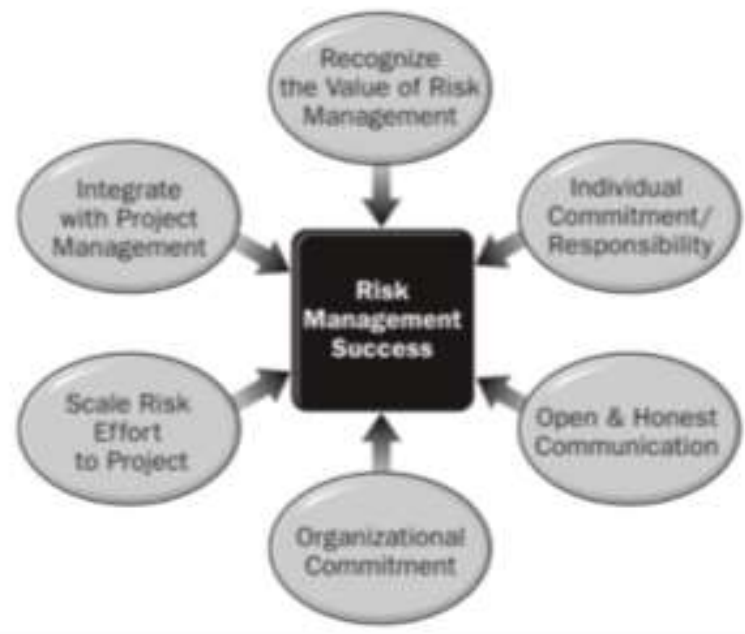

Figure 3: Risk Management Critical Success factors

1. Resistance to change: this is most common barrier for implementation of effective project risk management because usually employees are resistant for new concept.

2. Lack of clear risk definition: as discussed previously, there is no clear definition of term 'risk', because of these employees remain unclear about the implementation of concept;

3. Limited top management support: many studies believe that without support of top management or without proper leadership, organization unable to get goal-oriented direction and strategic vision.

4. Limited availability of resources: According to Hwang, Zhao, and Toh (2014) like funds, technologies and work force are some of the important resources that can contribute to the success of implementation of project risk management strategy.

5. Lack of cooperation between top management and employees: this is an important criterion to bring the positive change, because proper relationships in top management and employees can create a favorable environment for developing effective project risk management.

6. Lack of formal training: For effective project risk management practices training are important determinant as per Papadaki et al., (2014), because untrained people can become a limiting factor in implementation and effective use of risk management practices as mentioned by Dandage et al., (2017).

7. Increased cost risk management: risk management strategies if not implemented successfully it can disturb the economic budget of project and drive cash flow to negative balance.

8. Avoidance of talking about risk: As per Bhoola et al., (2014) avoidance of talking about risk within an organization usually positive things are discussed among tea, but 
they often avoid talking about shortcomings and draw backs. This can create miscommunication between employees and top management.

9. Cross-functional conflicts: team members of a project usually belong to different functional departments within a company, this situation can create functional conflicts among team members.

10. Cultural differences: Harner (2010) clearly highlighted the importance of solid relationship between management practices and corporate culture.

\subsection{Effective aspects for application of successful risk management practices}

Numerous researchers tried to examine the CSFs in respect to project management context, but still the magnitude to research in this area is insufficient. For instance, as per Hosseini et al. (2016) inspected the CSFs for applying risk management in emerging nations. The investigators found that there are four highly important factors:

- Top management support

- Knowledge and awareness of the process of risk management

- Adequate education and training

- Organized method of project delivery

For successful implementation of project risk management PMI (2009) constructed the practice standard and also acknowledged the importance of CSFs. PMIs Project Risk Management Critical Success Factors are shown in Figure 4 (PMI. 2009)

The guideline given by PMI identifies six (6) CSFs for project risk management, including: In the oil and gas sector improving time, cost and quality management practices is requirement for efficient management of policies, which ultimately drive the knowledge to minimize future losses and failure rates. Al Subaih , Carvalho \& Rabechini Junior, (2015) also stated in their studies that project failure can be reduced if all the risk factors are carefully identified and assessed this is one of the highly efficient practice in respect to implementation of project risk management.

\subsection{Performance of Projects in Oil and Gas Industries}

There is a complexity and difficulty in both technology and management of oil and gas industries, due to this oil and gas projects are considered to be the most challenging of all industries as per Akinremi et al., (2015). However, Briel et al. (2013) proposed that in addition to experience, project managers should follow coherent reference framework and that should be based on constant monitoring and reviewing of all official project stages from starting to finish the project. Finally, it can be stated that developing management 
strategies in relation to time, cost and quality is all that necessary for an efficient management in all oil and gas sector, this will ultimately enforce the requirement of knowledge to reduce upcoming possible project failure events.

Project failure can be minimized by careful assessment of risk factors and this is one of highly effective project risk management strategy as mentioned by Al Subaih, (2015). However, importance of risk management is all known but still some oil and gas industry projects are facing failure due to lack of proper implementation of risk management strategies.

\subsection{Project Risk Management Studies in Oil and Gas Company in GCC}

The most recent study was done by Muralidhar (2010) in context of Arab world, specifically the Gulf Corporation Council (GCC). 'To investigate the methods of Enterprise Risk Management (ERM) in oil and gas companies' was the main purpose of this study. The researcher of this study emphasized the necessity for an ERM implementation and recommended additional research as a conclusion, because this area of research is newly emerging. Within the oil and gas industry in Gulf region, in Arabic world and more specifically in Saudi Arabia, Saudi Aramco is dominant oil and gas sector. It is a state-owned company. In reality, the biggest global oil and gas production company is Saudi Aramco as per report by Aramco, (2013). The company knows the necessity of project risk management as a vital essential component within company's cooperative strategy, 'Saudi Aramco Enterprise Risk Management has been recently established by Saudi Aramco Company is confident and guarantees that this risk management strategy is helpful for company's decision making and planning processes as reported by Aramco (2013).

\subsection{Summary}

Purpose of the study was to conduct a comprehensive review on importance and effective practices of risk management in the oil and gas industry. This review provides the limitations to the effectiveness of such practices to enhance project performance. Finally, the researchers provide an actual image of oil and gas industry with the facts like poor performance, over budgeting, delaying, lack of proper tools and experienced work force and these all limitations having their roots in lack of implementation of project risk management practices. Several researches and theories are available on Risk management as mentioned above which indicates positive relation between risk management process and Oil and Gas industries. Risk management process has been widely applied by several oil and gas industries around the world and also in Kingdom of Saudi Arabia. Risk management and mitigation are challenging issues which needs proper planning and application to control risk and risk factors in an organization. Moreover, there are several procedures applied to control and manage risk through the application of specific tools and measures as mentioned in risk management tools and techniques Table 1. For this study the mentioned tools and techniques will be utilized as part of the findings to determine whether the management in the organization are aware of the tools and techniques, and which among the mentioned are applied to control and manage risk. 


\section{Research Methodology}

For this study we have used two different research approaches. One being the qualitative method through which semi- structured interviews will be conducted with management of different departments whereas the other method is the Quantitative method, where the employees will be included in a survey

\subsection{Research Sampling}

Two groups were targeted from an oil and gas company in the Kingdom of Bahrain. The first group for the Quantitative method comprises of managers whereas the second group the participants of the survey, questionnaire was distributed among all the employees in the department through survey links. Both groups were assessed using qualitative as well as quantitative method respectively to analyse their knowledge, perspective, and skills involved in Risk management.

The Survey questionnaire was designed using 20 questions (Appendix 2). The questionnaire was structured based on Likert's 5-point scale which ranged from the scale of $1-5$, with $1=$ strongly disagree, $2=$ disagree, $3=$ Neutral, $4=$ agree and $5=$ strongly agree. The questions were designed to evaluate the understanding and knowledge of the employees such as engineers, specialists, officers, etc. based on the risk management strategies applied in the company. The questionnaire comprises of tools which analyses the awareness, and readiness of risk management in the work environment.

\section{Sample size}

The study was conducted in order to reach the objective of the project. The sample of the populations involved in this study was selected based on non- probability sampling method. The population involved were from 4 divisions which included managements as well as employees for the survey. For the Semi structured interview, 10 managers were approached. Interview questions were structured based on the research question and the objective of the study to serve the purpose of analysing the risk management practices in the Oil and gas company and the different risk management tools applied by the company to monitor and control risk.

The survey questionnaire was distributed among the employees through survey link and the response received from the survey was from 124 employees and the response rate was for the survey was $17.71 \%$ of the total employees approximately (700 employees). There might be several factors involved on the low response from the employees, one being the implication of social distancing due to current COVID- 19 Pandemic. Other factor involved is the change is shift and lack of appropriate communication to attempt the survey. 


\section{Data Analysis}

\subsection{Introduction}

Chapter four is based on the analysis of the data collected from two applied methods which is quantitative as well as qualitative. After collecting the data, the statistical analysis was conducted using Microsoft Excel. Cronbach's alpha used for the calculation of internal consistency reliability.

\section{Data Analysis Method}

The data collected through the survey question was analysed using statistical analysis. The data collected through the survey questions later imported to IBM SPSS (Statistical Package for Social Science) version 23.0 and performed descriptive analysis for explain the participants' characteristics, discrete variables expressed as frequencies and percentages and continuous variables expressed as mean and SD. Reliability of the instrument assed using the Cronbach's alpha.

\subsection{Reliability of the Survey instrument}

The reliability analysis done by calculating Cronbach's alpha and Cronbach's alpha of at least 0.70 was taken as an indication of satisfactory reliability of each composite scale. The internal consistency is used to measure the reliability of a summated scale where several items are summed to form a total score.

\subsection{Results}

This survey questionnaire was based on four main factors to evaluate the employees' perception and those factors were the Objective settings, internal environment, information communication, and monitoring. The results for the survey are as mentioned below: The demographic characteristics of the participants has been explained in table one. The participants with higher respond percentage belonged to the age group $20-30$ $(43.44 \%)$ and years of services was $1-5$ years $(39.67 \%)$ with highest responses percentage from Oil processing Department with (48.39\%). The response rate for the survey was $17.71 \%$ of the total employees approximately (700 employee) from the 4 divisions. 


\subsection{Factor 1. Objective Setting (Objectives set by the organization for Risk Management)}

Graph 1. Objective Setting - Response graph

Based on the frequency result for Factor 1, the data finding indicates that the organization has a clear objective setting. the employees agree and strongly agree to Q 1 . Which is management having a strategic plan for risk management and they also displayed positive response towards having a set policy and clear objectives and approach for risk management.

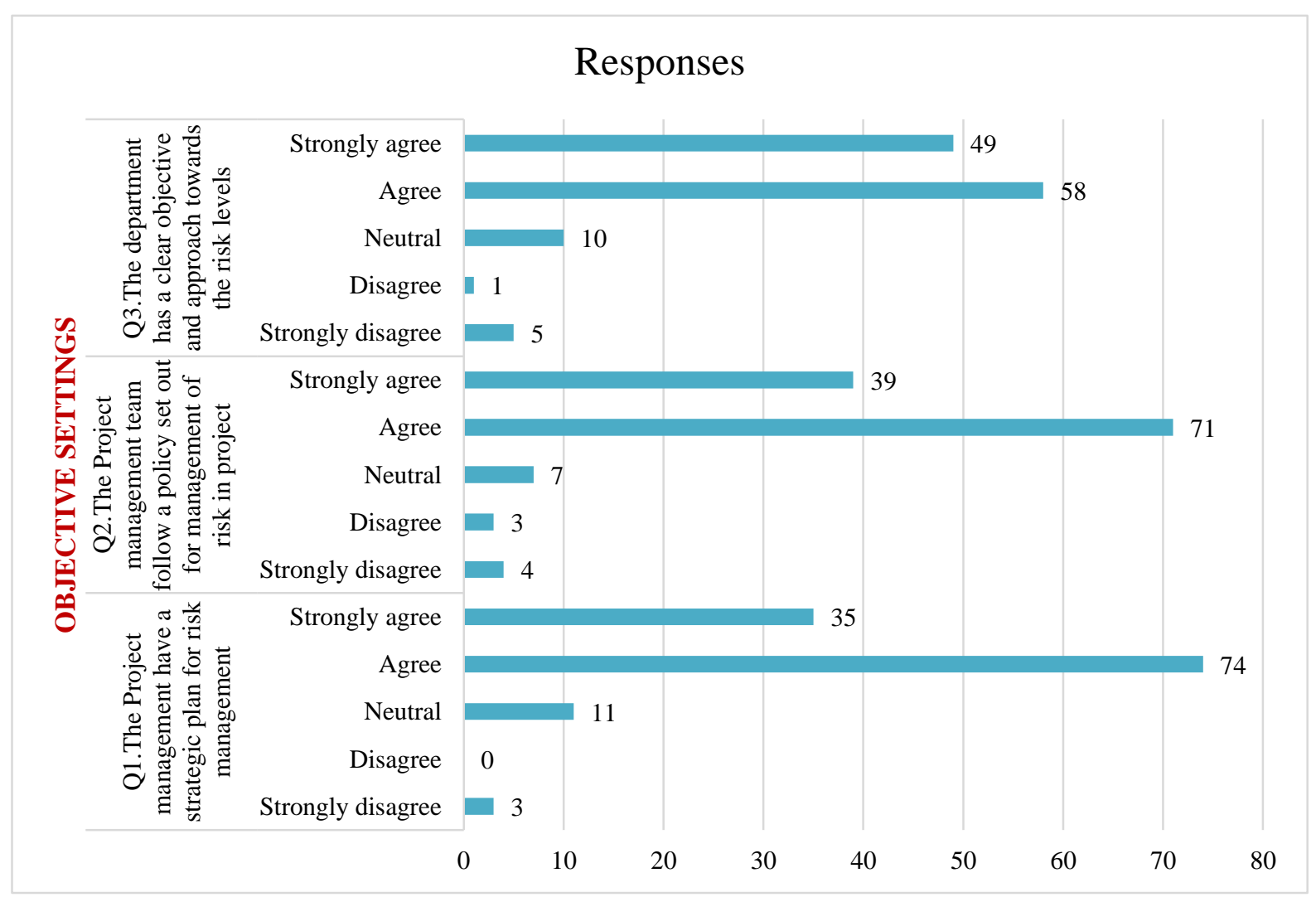

Graph 2.- Response graph - Internal factors

In response to the analysis of Internal factors, (55.65\%) employees agree and $29.8 \%$ strongly agree to Q.4, which is the usage of specific risk management tools. Moreover, as per response for Q.5 (62\% agree and $25 \%$ strongly agree) and Q.6, (55.6\% agree and $29.8 \%$ strongly agree) to the fact that risk management is planned during the initial project planning and both management as well as employees are involved in periodic review and risk management planning exercise to monitor, identify, and manage risk. 


\section{RESPONSES}

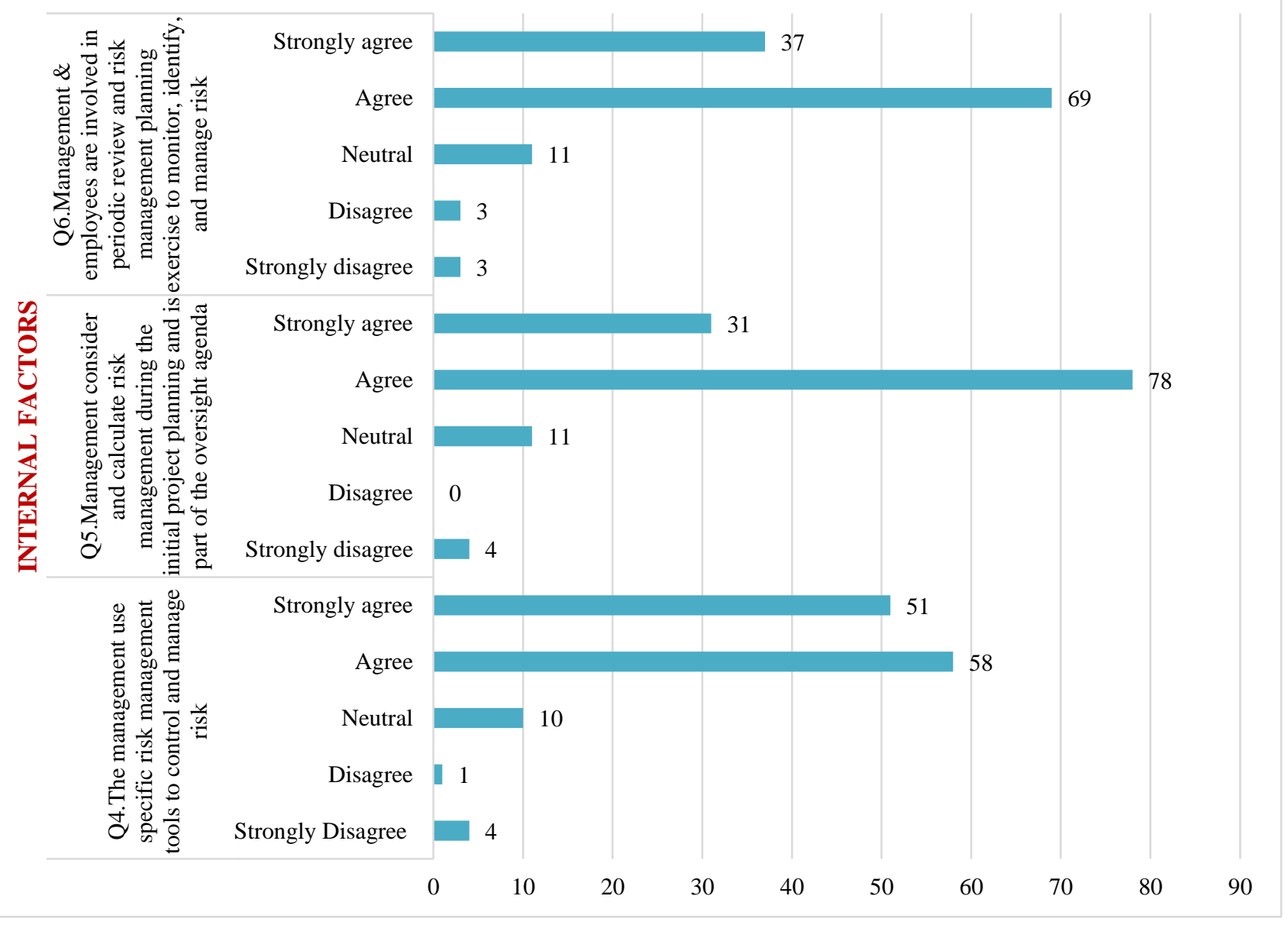

Graph 3. Response graph - Information Communication

Based on the results indicated, in table 4.5, majority of employees agree to having appropriate information communication between the management and employees. (52.4 $\%$ agree) over risk management policy, regulations, strategies to monitor, control and report risk factors and around $66.1 \%$ employees agree that the management clearly state the responsibility and accountability for identification of risk. Moreover, the employees agree that self -assessment is practiced at all stages from top management to representatives at the level of employee 


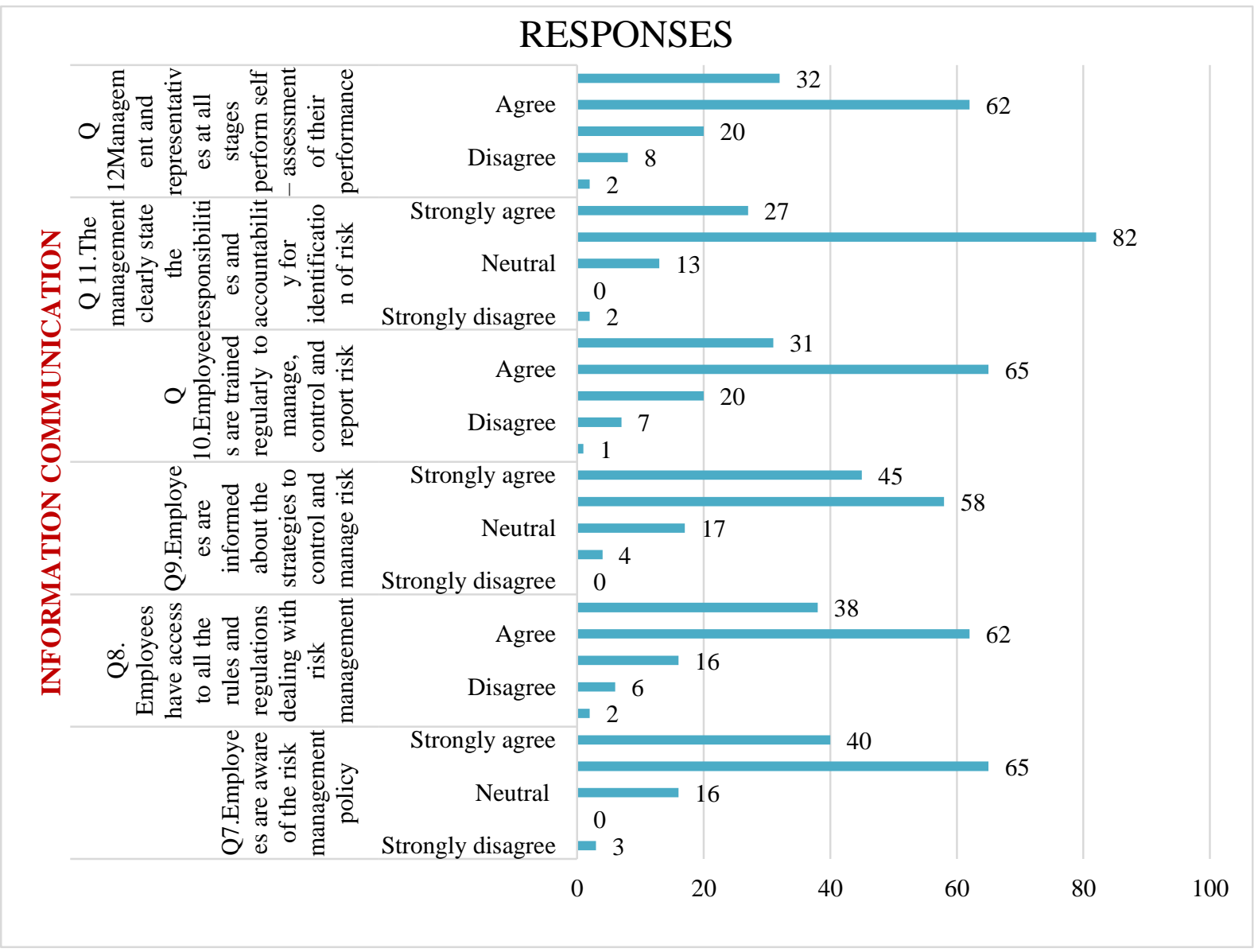

Graph 4. Response graph - Monitoring

The above table indicates that around $52 \%$ employees agree and $26 \%$ strongly agree to having adequate training to overview potential risk and to report them. The employees agree on daily monitoring procedure for risk and performance measure is used in monitoring result of risk management. However, approximately $17 \%$ if employees responded as neutral and $5 \%$ of employees disagreed and strongly disagreed (5\% for each) with the application of Monitoring strategies in the organization. 


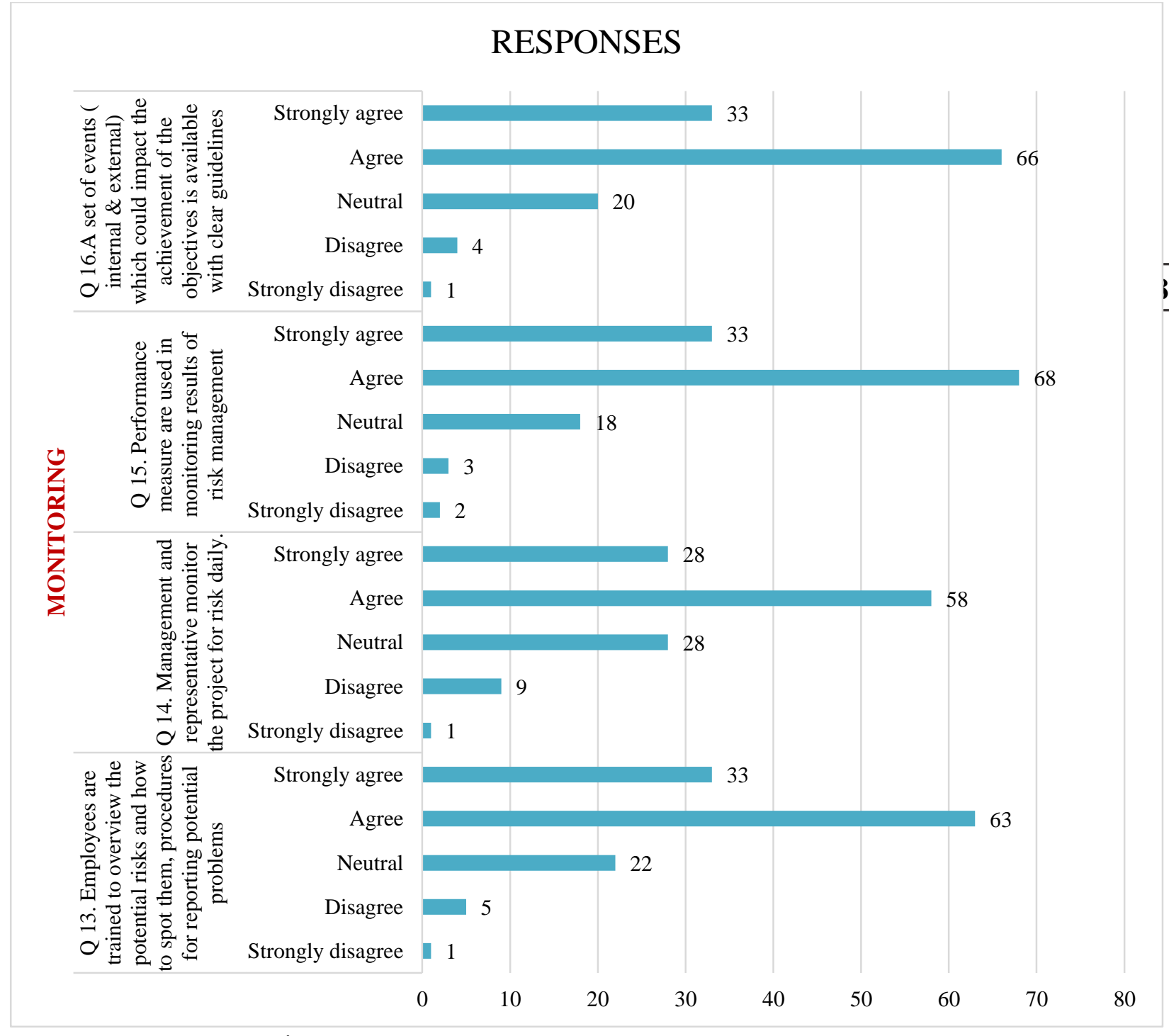

Figure 4 Monitoring graph

\section{Reliability Analysis}

The final questionnaire consisted of 16 items. The reliability of the instrument was represented by a Cronbach's $\alpha$ of 0.913 , which is greater than the minimum required alpha of 0.70 .

Table 4.1: results of the Reliability test of the 16 items from the questionnaire for employees' perception and awareness of the risk management tools and procedures in the organization. This indicates that the survey questionnaire has very high reliability- 


\section{Reliability Statistics}

Cronbach's Alpha $\quad$ N of Items

.913

16

Table 2Reliability Statistics

\subsection{Questionnaire Statistic}

Table 4.2 indicates the item statistics, where the mean and standard deviation of each item (question in the questionnaire) is providing. As per the above table, the mean of most the items from the questionnaire is between $1.7-1.9$ which indicates that the respondent strongly agrees to the items assessed. However, only 3 items from the 16 items have a result of mean between 2 to 2.18, which indicates that the participants agree to the evaluated items.

\begin{tabular}{|l|l|l|l|}
\hline Questionnaire Statistics & & & \\
\hline & Mean & $\begin{array}{l}\text { Std. } \\
\text { Deviation }\end{array}$ & $\begin{array}{l}\text { Cronbach's Alpha } \\
\text { if Item Deleted }\end{array}$ \\
\hline $\begin{array}{l}\text { The project management team follow a } \\
\text { policy set out for management of risk in } \\
\text { project }\end{array}$ & 1.89 & 0.874 & 0.908 \\
\hline $\begin{array}{l}\text { The department has a clear objective and } \\
\text { approach towards the risk level }\end{array}$ & 1.82 & 0.927 & 0.906 \\
\hline $\begin{array}{l}\text { The management use specific risk } \\
\text { management tools to control and manage } \\
\text { risk }\end{array}$ & 1.79 & 0.884 & 0.907 \\
\hline $\begin{array}{l}\text { Management consider and calculates risk } \\
\text { management during the initial project } \\
\text { planning and is part of the oversight agenda }\end{array}$ & 1.93 & 0.8 & 0.908 \\
\hline $\begin{array}{l}\text { Management and employees are involved in } \\
\text { periodic review and risk management } \\
\text { planning exercise to monitor, identify, and } \\
\text { manage risk }\end{array}$ & 1.91 & 0.843 & 0.907 \\
\hline $\begin{array}{l}\text { Employees are aware of the risk } \\
\text { management policy }\end{array}$ & 1.89 & 0.815 & 0.91 \\
\hline $\begin{array}{l}\text { Employees have access to all the rules and } \\
\text { regulations dealing with risk management }\end{array}$ & 1.95 & 0.871 & 0.906 \\
\hline $\begin{array}{l}\text { Employees are informed about the strategies } \\
\text { to control and manage risk }\end{array}$ & 1.84 & 0.786 & 0.912 \\
\hline
\end{tabular}




\begin{tabular}{|c|c|c|c|}
\hline $\begin{array}{l}\text { Employees are trained regularly to manage, } \\
\text { control and report risk }\end{array}$ & 2.06 & 0.846 & 0.906 \\
\hline $\begin{array}{l}\text { The management clearly state } \\
\text { responsibilities and accountability } \\
\text { identification of risk }\end{array}$ & 1.93 & 0.682 & 0.907 \\
\hline $\begin{array}{l}\text { Management and representatives at all } \\
\text { stages perform self- assessment of their } \\
\text { performance }\end{array}$ & 2.09 & 0.909 & 0.903 \\
\hline $\begin{array}{l}\text { Employees are trained to overview the } \\
\text { potential risk and how to spot them, } \\
\text { procedures for reporting potential problems }\end{array}$ & 2.02 & 0.833 & 0.905 \\
\hline $\begin{array}{l}\text { Management and representatives monitor } \\
\text { the project for risk daily }\end{array}$ & 2.18 & 0.891 & 0.91 \\
\hline $\begin{array}{l}\text { Performance measures are used in } \\
\text { monitoring results of risk management }\end{array}$ & 1.98 & 0.813 & 0.909 \\
\hline $\begin{array}{l}\text { A set of events (internal and external) which } \\
\text { could impact the achievement of the } \\
\text { objectives is available with clear guidelines }\end{array}$ & 1.98 & 0.803 & 0.909 \\
\hline $\begin{array}{l}\text { The project management have a strategic } \\
\text { plan for risk management }\end{array}$ & 1.88 & 0.767 & 0.909 \\
\hline
\end{tabular}

\subsection{Result of Interview - Management perception on Risk Management}

The aim of this section was to understand the awareness and preparedness of Management based on the study topic of risk Management. N- Vivo software was used to highlight the similarity in the answers of the participants' responses. Moreover, for more accuracy and confirmation the responses were analyzed manually and were compared with the response achieved through the software, to eliminate any bias and error in the results. 


\section{Semi- Structured Interview Question Theme}

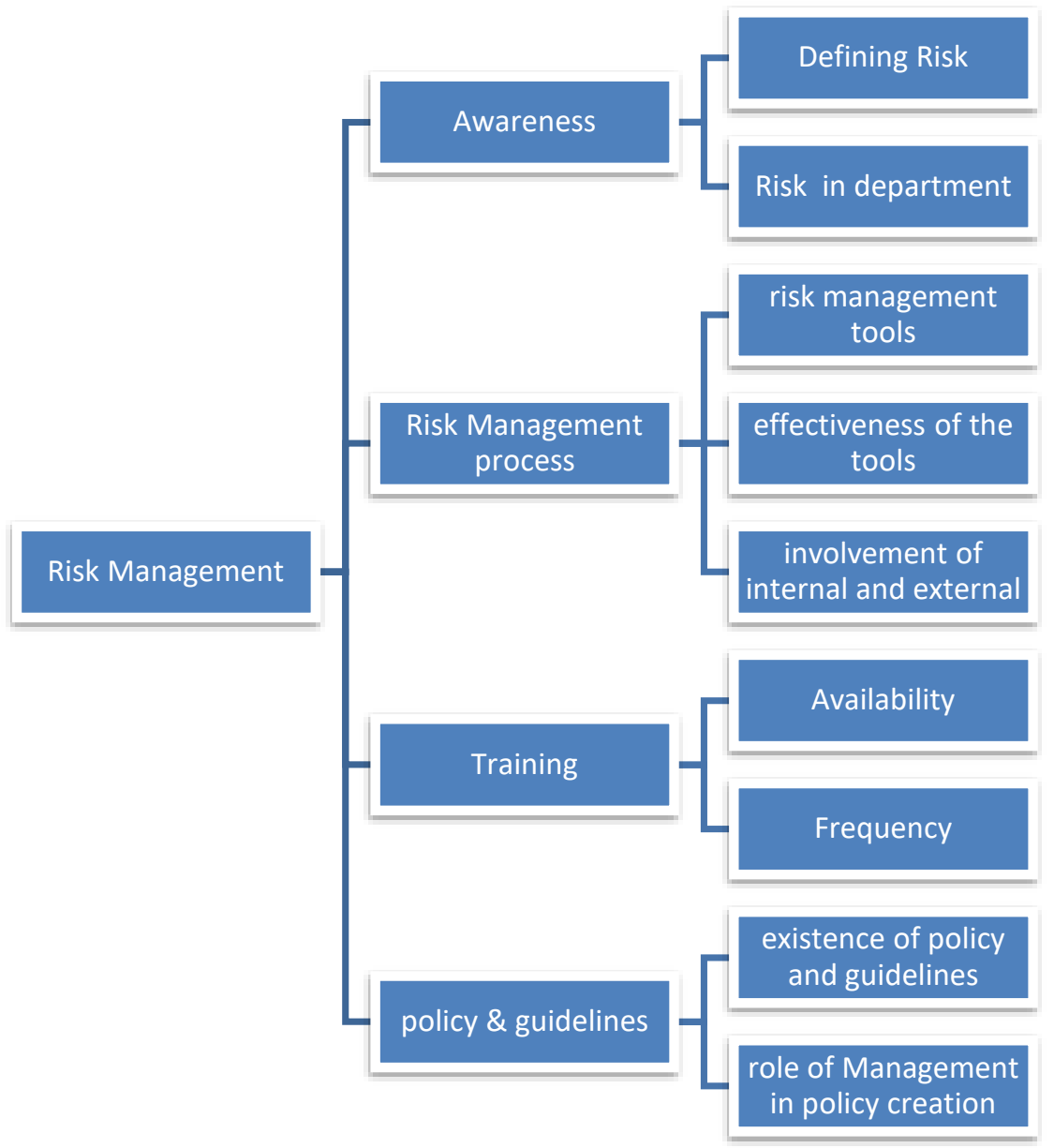

Figure 5 Semi - structure Interview Question themes

\section{Definition of Risk}

The first open- ended question that was probed on the participants was to understand their knowledge and understanding of Risk. The question that was asked was "How do you define Risk in your company". Based on their responses we could determine that every participating individual has their own perspective and definition of risk. Among the responses, most common response was Hazard, damage, and the Likelihood of Hazard causing incident. However, other perceived risk to be lack of security, and "anything which can impact the estimated cost and schedule of a project". Risk was also defined by a participant to be "different aspects, business, process, safety, etc. and accordingly they are eliminated or mitigated."

Based on this evaluation we can state, that Risk most commonly is defined as hazardous, to business, products, life and has a negative impact and cause financial and environmental damage. 


\section{Risk Faced within the Department}

As the interview was done with the management of different department, the posed question was with the intention to understand the risk factors in each department, the question asked was "What are the risk faced by your department".

Based on the result as indicated in the above figure, the participants referred to several recurring issues faced by individual departments such as flammable risk due to hazardous products such as Hydrocarbon, operations risk, health and safety risks, project execution. Around 3 participants out of 10 ( $30 \%$ ) referred to risks due to process and personal factors, whereas majority of participants referred to risk due to hazardous and flammable substances mishandling, exposure and inhalation, whereas some also mentioned environment issues such as wind, dust, heat, cold, and rain to be among the risk factors in their department.

\section{Structured Procedure and policy to manage Risk and who constructs the policies and guidelines of Risk Management}

All of the 10 managers (100\%) agreed to have a structured policy and guideline to manage risks in their department. Participant also responded that "Well several standards - such as "Process Safety standards, PTW standards, Environment management system." Two participants commented that they have policy and procedure at all stage including design stage, operation and maintenance stages, and procedures to prevent emergencies and other control risks once they occur. For environmental risk control, participant informed that they have procedures for the disposal of solid and liquid waste and also a standard for handling toxigas like H2S standards etc.

\section{Q.8 Policy and Guidelines Managers}

Moreover, 6 out of the 10 participants (60\%) stated that the departments management and HSE construct the policies and guidelines for the organization. Participant also informed that "Multidisciplinary team, which made up from HSE department and other stakeholders such as oil storage and export department" are involved in the policy and guidelines construction for the organization.

\section{Applied Risk Management structures and processes in the department $(Q 9, Q 10)$}

Based on the result of the responses, two participants' ( $20 \%$ ) response to risk structures, "Hazards are identified, evaluated and ranked based on its likelihood and consequences. Adequate mitigation measures are taken as governed by Risk Matrix" whereas others informed that the risk structure is a calibrated risk matrix to assign likelihood and consequence. Participants also replied that the risk management structures are Business Resilience, Business continuity, risk-based work selection, ISO certification, International hierarchy. However, one of the participants also stated that they were not sure of what it means. 
Furthermore, as per the responses by the participants, the most applied risk management processes in the organization are Hazop which has been frequently referred to by the managers. Other such processes applied are MOC, JSA, RAMS, Risk Matrix, Business continuity. Participants ( $30 \%$ ) also stated that HSE management system and Operational excellence are also applicable processes for risk management in the department.

\section{Q.11 Involvement of Employees (Internal / External employees)}

Based on our next questions (Q11 and Q 12.) How many employees involved in the Risk Management process and Whether Internal employees were trained adequately, or External Employees are involved. The majority of response (80\%) received was that all employees within the department are involved by following procedures, job requirement and actively taking part in the BOOST etc. Moreover, it was also stated that external employees such as contracted employees do play role in the involvement of risk management.

Furthermore, in terms of training the respondent response was in affirmative to have received adequate training, confirming that both internal as well as external employee are trained, and that both are qualified to receive the required training based on their departmental needs. however, there were also employees $(20 \%)$ who denied receiving any training. The denial can be based on the fact, of their job position and training requirement.

\section{Types of Training and Frequency $Q 13$ and Q 14}

Q13 and Q 14 were based on enquiring about the type of training and the frequency of training. For type of training, the response varied from employee to employee and the similarity, was based on the respondent from a single department.

The most common responses which is 7 out of 10 , were as per the above image which states that the participants receive mandatory training related to safety, PTW (Permit to work), RAMS training related to awareness, PSM. The other common category for recommended training were in- house trainings, Fire analysis, Job Safety Analysis training, defensive driving. Moreover, the participants also listed other categories of training which such as MOC $<$ HAZOP, BOOST, Working on height.

Moreover, in terms of frequency the common responses were that training was provided based on procedure and identified need basis. participant also informed that there is no specific period, and that some training is offered "monthly and on ADHOC basis. These trainings are structures with intended outcomes and assessments to ensure learners achieved these ILOs". There was also one respondent (1\%) who claimed that there was no training available. The frequency of negative comment is lesser than the affirmation of having periodical training based on requirement and needs. The negative comment can be based on the employee's educational and job background. 


\section{Q 15 Top Management Role in Risk Management}

Based on the responses, $(40 \%)$ it was determined that the top management are the bodies who ensure the proper process of risk management in the organization. "They sign off on the Enterprise Risk Register, they set agenda for risk reduction and toleration". Moreover, one respondent also informed that "Management take ownership and responsibility (patronize and champion the Risk Management Process and its implementation. Other 5 responses $(50 \%)$ were also based on the managements responsibilities towards monitoring and governance the adequacy, effectiveness to compliance act as a decision review board, and also, they approve or not approve the risk assessment.

Based on the above responses, Management play a vital role in the implementation, monitoring and taking responsibilities of Risk management.

\section{Techniques applied from Risk Management tools to manage and control risks}

These questions were based on the Risk Management tools widely used, applicability and effectiveness of tools for managing and controlling all risk types based on our objective. In respond to the above questions (Q 16, Q 17, Q 18), from among the proposed 33 risk management and controlling tools (refer to table 1 . Tools and techniques) provided to choose from,

The tools and techniques used by most of the department as per the responses is indicated as per the above figure. As per the responses that most common tools and techniques are based on the response is Hazard and operability with a maximum of 8 respondents $(80 \%)$ have stated on applying this method along with incident report. Furthermore, the next most applied tools and techniques based on the responses are the 5 why's, change analysis, checklist, risk ranking, and cause effect. Moreover, the least used tools and techniques as per the responses are the decision tree, fault tree, event tree, and human reliability which has been the least occurred in the responses.

However, almost all the respondent (100\%) stated that not the same tools are applicable for all types of risks. "nature of risk and the job requirement, the tools are selected and used". Whereas the other respondent who elaborated further was that "Some related to personal risks e.g. 5 - whys, while others are applicable to process risks e.g. what if, hazard and operability".

When questioned about the effectiveness of the stated tools, the participants $60 \%$ responded that the tools applied are "Effective managing and controlling risks". Four participants also stated that the tools and techniques significantly reduce the risk levels, while others stated that effective based on the culture and the training.

\section{Risk Management or Risk Control}

Our next question Q.19, "Do you believe in Risk Management or Controlling the Risk factors?' 
Majority of our participants approximately $70 \%$ believed in Managing as well as controlling the risk factors. "Managing risks involves controlling the risk factors". Other participant stated that it is preferable to analyses all scenarios and associated risks. Furthermore, one of the participants added that "following the standards and procedures, safety tools, implementing the recommendations with proper MOC's, operating the units as per the procedures and within the design limits etc."

Hence based on the above information, it can be stated that managements believe in managing and controlling risk and risk factors in order to ensure the status of risk and apply corrective measures and preventive actions.

\section{Challenges related to risk tools and how do you deal and manage the challenges.}

The next question was based on the challenges with the risk tools utilized in the departments. The participants had their own view based on the challenges, where one participant stated that there are challenges and they are well managed like the team member commitment for which they follow up on the implementation of gaps, etc. whereas the other stated that every process within the department has its own challenge and we learn to improve systems and processes and make don't have repeat of those situation.

One participant found that culture prevents people speaking up about hazards, so no control or mitigations put in place. Based on this reply, it is unsure whether the participant referred to the local culture, or the organization culture which makes it difficult or the cultural variances amongst the employees, where it becomes difficult to communicate adequately due to language restrictions. A participant also stated that, the challenges doesn't lie in the tool, but the way it is used. And stated the importance of being trained to use the tools for correct handling and usage.

\section{Types of risk and challenges in the Department which is barrier to risk management.}

In response to Q 21, each participant has their own sets of challenges, based on their department or through personal experiences. The challenged stated by each participant were:

- Training of external workforce involved in construction and implementation of project.

- Update of workforce with procedure and implementation of control measures

- Lack of awareness and purpose by some PCED staff

- Inability to see benefit of risk management by some PCED staff

- Routine, acceptance, being lazy, poor design, time, lack of fund, poor maintenance, missed inspection, poor auditing, etc.

- IT system crash, travel bans for experts to visit the site

- Human behavior, normalizing deviation, getting employees to maintain vulnerability

- Emergency situation due to unfavorable conditions, weather COVID situation, 


\section{Suggestions and recommendations for managing Risk}

The participants stated that the organization requires to improve project execution risk management. Change should be made in the culture that is followed to minimize risks. Moreover, other participant suggested that experts should achieve and eye for reviews and feedbacks. "Continual improvement is key to optimizing risks". Moreover, there were also suggestions of implementing external audits, to ensure best practices around the world. Participant suggestion the organization was that "including a section that explicit address human performance / factor in the risk management procedures. Human performance should be one focus area in any risk management initiative whether related to personal or process safety.

\subsection{Discussion}

Based on the above data from the semi- structured interview and the survey questionnaire, the following are the analysis, the discussion is stated based on the results of our analysis for both the participating groups.

\section{Objective 1. Major risks and issues that influence the projects in oil and gas industries}

As stated in the literature review (2.2 risk factors) and through the results and findings of this study, there are internal as well as external risk factors faced by oil and gas company. The same is also mentioned by our participants. Internal risks comprise of financial, investment, property, human resources, management, innovations, information, production operational, technical, technological, liquidity whereas external risk comprises of geological, weather, globalization etc. Hence based on this factor, we justify objective 1 of our study to determine major risk factors involved.

\section{Objective 2. standard guidelines and procedures}

Based on the results of the data collected, it was found that the organization has clear policy and structured guidelines for risk management. The various policy and procedure guidelines that the company apply are the Project risk register, policy for personal risks such a s four Key tool safety rules, stop to work Authority (STW). Hence, from the above we can determine our next objective of having a structured policy.

\section{Objective 3. Current risk management tools and strategies}

the organization apply certain selective tool in the departments. The tools are said to be effective in terms of their characteristics in handling risk. Each risk tool as per the participants are specialized and are selected based on the applicability to the risk factors.

\section{Objective 4. Employee's involvement in project risk management strategy}

Each employee regardless of their position high management to employees are involved in risk management. As per the result of the findings, both managers and employees are 
trained adequately to monitor, evaluate and report risk and risk related factors. the organization has appropriate training procedures and each department ensure that the employees involved have the right skills and knowledge to involve and assess risk and risk factors.

\section{Objective 5. Safety precaution and pre-planning of risk management are applied to ensure human and environment safety}

As per the data and information provided by the participants, the company in the Kingdom of Bahrain has implemented several safety precaution strategies. Moreover, the management has a vision of "Zero Injury", hence a daily monitoring and report is prepared by departmental supervisors and heads to ensure the safety of the employees and workplace to eliminate any risk which could be hazardous to life and property.

\subsection{Summary}

- In terms of definition of risk, the majority of participants consider risk to be hazardous to business, products, life and has a negative impact and cause financial and environmental damage

- Risk and risk factor vary from department to department based on the nature of their tasks and function within the organization

- There is a structured policy and guideline within the department and the top management, HSE are responsible bodies to construct the policies and guidelines

- Both internal as well as external employees (contractors, etc.) are involved in risk management and adequately participate in management and control of risk based on their job

- Employees are provided with adequate training based on the nature of their job and the training is organized based on the departmental needs

- The top management play a vital role in the monitoring, implementation and process of controlling risk and risk related factors, while taking the responsibility of handling risk and risk related incidents and occurrences within the department and organization as a whole.

- Among the many risk management tools and techniques, specific types of tools and techniques have been utilized by the organization and based on the risk factors, the tools are used. 


\subsection{Conclusion}

The Oil and Gas industry plays a crucial role and contributed greatly towards the development and financial health of the Kingdom of Bahrain. The study was based on the objective to understand the risk and risk related factors in the oil and gas industries. To reach the objectives of the study, data was collected through literature review of similar studies, and through qualitative and quantitative study. Based on the result and findings, through the literature review, survey and interview this study identified the major risk related issues in the company and measures applied by the company to control and manage risk. The company apply several control and monitoring measures to determine the risk factors and use different tools and techniques to measure and control risk. Adequate training and educational process are applied to enhance the knowledge and skills of employees at all level to monitor, identify, control and report risk issues.

\subsection{Limitation of the Research}

1. The research study is confined to risks and risk management implications in projects in the oil and gas company. Strategies applied toward controlling and managing risks are analyzed in this research study.

2. This study only limited to project and project management department, but not the all other departments in oil and Gas Company. The main area of focus of this study is the various stages of projects in the company.

3. The result is based on the various risks faced by the project department and different strategies applied in order to control the challenges and drawbacks related to the risks. Moreover, employees' involvement in the implementation of proper risk management strategy will be analyzed along with strategies and pre-planning of risk management applications to ensure safety to human and environment

4. The response rate of the employee was low and there can be several factors related to the low response.

5. The organization has duty based on shifts, and possibility of lack of proper communication is high.

6. Moreover, during the time of data collection, Social distancing was implemented, and several organizations were following work from home. Moreover, employees might not be aware of performing survey or following survey link based on their education level and job.

\subsection{Recommendation}

Based on the recommendation and suggestions of the participants and in line with the results we can recommend: 
- The HR department can have certified training for employees at all level and evaluate the performance on frequent basis so as to eliminate any reason for mishap due to untrained employees

- Another important strategy that could be employed to mitigate the risk of incompetence of project team is good staffing. Organization's Human resource department and authorities should observe the right skill in the employees and allocate them to projects which could benefit from the talent and knowledge.

- Management should focus on risk management initiatives by each individual and section within the organization that explicitly address human performance and factors in the risk management procedures

- The higher management of the company should develop a culture to follow risk minimization practices within the departments

- The organization should divide the risk sources into controllable and non- controllable risk which can make it easier for the organization to plan risk mitigation to eliminate the risk and risk related factors

\section{References}

Aven, T., Vinnem, J. E., \& Wiencke, H. S. (2007). A decision framework for risk management, with application to the offshore oil and gas industry. Reliability $\begin{array}{llll}\text { Engineering \& System } \quad \text { Safety, } & \text { 92(4), }\end{array}$ https://doi.org/10.1016/j.ress.2005.12.009

Benta, D. P. M. \&. M. C. (2011). On Best Practices for Risk Management in Complex Projects, Informatica Economica Journal, pp. 15(2), 142-152.

Bhoola, V. H. S. \&. M. D. (2014). An Assessment of risk response strategies practiced in software projects. Australasian Journal of Information Systems, p. 18(3). https://doi.org/10.3127/ajis.v18i3.923

Cagliano, A. C. G. S. \&. R. C., (2015). Choosing project risk management techniques. A theoretical framework. Journal of Risk Research, pp. 18(2), 232-248. https://doi.org/10.1080/13669877.2014.896398

Carvalho, M. M. d. \&. R. J. (2015). Impact of risk management on project performance: the importance of soft skills. International Journal of Production Research, pp. 53(2), 321-340. https://doi.org/10.1080/00207543.2014.919423

Dandage, R. V. M. S. S. R. S. B. \&. B. V. (2017). Analysis of interactions among barriers in project risk management. Journal of Industrial Engineering International, pp. 117. https://doi.org/10.1007/s40092-017-0215-9

Fauver, L. a. N. A. (2012). Derivative usage and firm value: the influence of agency costs and monitoring problems. Journal of Corporate Finance, pp. 719-735. https://doi.org/10.1016/j.jcorpfin.2010.09.001

Harner, M. M. (2010). Barriers to effective risk management. Seton Hall Law Review., pp. 40(4), 1323-1365.

Herkenhoff, L. (2014). A Profile of the Oil and Gas Industry: Resources, Market Forces, Geopolitics, and Technology. Expert Press Industry Profiles Collection. 
Hillson, D. \&. M.-W. R. (2007). Understanding and managing risk attitude.. Aldershot: Gower Publishing, Ltd.

Hosseini, M. R. C. N. J. J. \&. A. M. (2016). Critical success factors for implementing risk management systems in developing countries. Construction Economics and Building, pp. 16(1), 18-32. https://doi.org/10.5130/AJCEB.v16i1.4651

Hwang, B.-G. Z. X. \&. T. L. P. (2014). Risk management in small construction projects in Singapore: status, barriers and impact. International Journal of Project Management, pp. 32(1)116- 124. https://doi.org/10.1016/j.ijproman.2013.01.007

Khvostina, I. e. (2017). Manifestation of emergent properties in risk assessment of oil and gas companies. s.l., s.n.

Liu, W. E. \&. C. C. E. H. (2015). Leveraging social capital to obtain top management support in complex, cross-functional IT projects. Journal of the Association for Information Systems, pp. 16(8), 707. https://doi.org/10.17705/1jais.00404

Nocco, B. W. \&. S. R. M. (2006). Enterprise risk management: Theory and practice. Journal of Applied Corporate Finance, pp. 18(4), 8-20. https://doi.org/10.1111/j.1745-6622.2006.00106.x

Papadaki, M. G. A. R. J. K. R. T. A. \&. B. M. (2014). Essential factors that increase the effectiveness of project/programme risk management. Procedia-Social and Behavioral Sciences, pp. 119, 921-930. https://doi.org/10.1016/j.sbspro.2014.03.103

PMI. (2013). A Guide to the Project Management Body of Knowledge (PMBOK Guide). Newtown Square, Pennsylvania:. Project Management Institute.

Rabechini Junior, R. \&. M. d. C. M. (2013). Understanding the Impact of Project Risk Management on Project Performance: an Empirical Study. Journal of technology management \& innovation, pp. 8(suppl 1), 6-6. https://doi.org/10.4067/S071827242013000300006

Sage, A. P. \&. H. Y. Y. (2015). Risk modeling, assessment, and management:. John Wiley \& Sons.

Suda, K. A., Rani, N. S. A., Rahman, H. A., \& Chen, W. (2015). A review on risks and project risks management: oil and gas industry. International Journal of Scientific Engineering, 6(8), 938-943.

Samson S, R. J. \&. W. M. (2009). A review of different perspectives on uncertainty and risk and an alternative modeling paradigm. Reliab. Eng. Syst. Saf, , pp. 94, (2) 558567. https://doi.org/10.1016/j.ress.2008.06.004

Schwab, K. (2016 . [Online] Available at: http://www3.weforum.org/docs/GCR20162017/05FullReport/TheGlobalCompetitiv enessReport2016-2017_FINAL.pdf

Thuyet, N. V. e. a. (2007). Risk management in oil and gas construction projects in Vietnam. International Journal of Energy Sector Management. pp. 1(2):175-194. https://doi.org/10.1108/17506220710761582

Wilson, R. S. A. (1997). Fundamentals of Risk Analysis and Risk Management. Uncertainty and variability in risk analysis.. Molak, V. (Ed.),: CRC Press, Boca Raton, FL,.

Zwikael, \&. A. M. (2011). The effectiveness of risk management: an analysis of project risk planning across industries and countries. Risk analysis, pp. 31(1), 25-37. https://doi.org/10.1111/j.1539-6924.2010.01470.x 